\title{
Does better availability mean better accessibility? Spatial inequalities in the care of acute myocardial infarction in Hungary
}

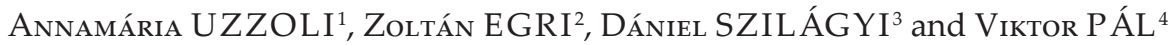

\begin{abstract}
The availability of health care services is an important issue, however, improving availability of health care services does not necessarily mean better accessibility for everybody. The main aim of this study is to find out how better availability in the care of acute myocardial infarction vary with accessibility of patients' geographical location within Hungary. We applied statistical analysis and interview techniques to unfold the role of spatiality in the conditions of access to health care. Results of statistical analysis indicate significant health inequalities in Hungary. Decreasing national mortality rates of acute myocardial infarction, has been coupled by increasing spatial inequalities within the country especially at micro-regional level. According to in-depth interviews with local health care stakeholders we defined factors that support access to health care as well as important barriers. The supporting factors are related to the improvement of availability (i.e. infrastructural developments), while geographical distance, lack of material and human resources, or low level of health literacy proved to be the most relevant barriers. Main conclusion is that barriers to accessibility and availability are not only spatial but are also based on individual stages of acute myocardial infarction care. The development of cardiac catheter centres in Hungary has improved the short-term chances of infarction survival, but long-term survival chances have worsened in recent years due to deficiencies in rehabilitation care as well as low level of health literacy.
\end{abstract}

Keywords: health care, health policy, infarction, health inequality, health literacy, deprivation, Hungary

Received May 2020, Accepted November 2020.

\section{Introduction}

The decline in mortality from cardiovascular diseases is one of the success stories in the most developed countries in the second half of the $20^{\text {th }}$ century. Although the mortality of cardiovascular diseases as well as coronary heart diseases has been halved in the last fifty years, it still remains the leading cause of death in developed countries (WILKINS, E. et al. 2017). Moreover, national health policies will face challenges in the future as the prevalence and costs of these diseases will probably increase due to ageing.

Acute myocardial infarction (AMI) is one of the most important cardiovascular diseases and this cause of death has no geographical, spatial, gender or social limit (HARPER, K. and Armelagos, G. 2010). National health care systems have to provide reasonable access to cardiac care for all citizens regardless of age, gender, race, socio-economic status or place of residence. However, a growing number of studies have shown that signifi-

\footnotetext{
${ }^{1}$ Geographical Institute, Research Centre for Astronomy and Earth Sciences. H-1112 Budapest, Budaörsi út 45. Hungary. Institute for Regional Studies, Centre for Economic and Regional Studies. H-1097 Budapest, Tóth K. u. 4. Hungary. E-mail: uzzoli.annamaria@csfk.mta.hu

${ }^{2}$ Faculty of Agricultural and Economics Studies, Szent István University. H-5540 Szarvas, Szabadság u. 1-3. Hungary. E-mail: Egri.Zoltan@gk.szie.hu

${ }^{3}$ Hungarian Central Statistical Office. H-1024 Budapest, Keleti Károly u. 5. Hungary. E-mail: Daniel.Szilagyi@ksh.hu

${ }^{4}$ Department of Economic and Social Geography, University of Szeged. H-6722 Szeged, Egyetem u. 2. Hungary.

E-mail: pal.viktor@geo.u-szeged.hu
} 
cant inequalities may exist within cardiac care, especially in relation to access to invasive cardiac care (cardiac catheterization) as well as cardiac rehabilitation care following an AMI case (Hassan, A. et al. 2009; Aso, S. et al. 2011). Some of these studies demonstrated the important role of geographical distance in access to cardiac catheterization facilities (PAtel, A.B. et al. 2007).

Buchmueller, T.C. et al. (2006) pointed out that increasing distances from hospitals resulted in higher death rates from heart attacks, and SEIDEL, J.E. et al. (2004) gave evidence that patients living farther from cardiac catheterization centres had lower adjusted rates of cardiac catheterization. Some authors came to the conclusion that although cardiac catheterization (percutaneous coronary intervention, PCI) as the part of invasive cardiac care could reduce mortality, enabling discharged patients to restore their health, but return to the society is still a public health problem to be solved in the current situation due to the inadequate rehabilitation (KJÆR, T. and GYRD-HANSEN, D. 2008). Other studies pointed out how delay times for call medical help (decision time) reduced long-term survival chance (YоNемото, N. et al. 2018). There are many studies which show that socio-economic status can also influence access to cardiac care. For example, Alter, D.A. et al. (1999) demonstrated that increases in neighbourhood income could increase in rates of cardiac catheterization following an AMI. Similarly, Rodrigues, E.J. et al. (2002) established marked regional variation in rates of cardiac procedures in patients who experienced an AMI in the province of Quebec, Canada.

While it is becoming increasingly evident that inequalities exist in access to cardiac care, relatively little is known regarding the effect of spatiality. Identifying and determining the geographical distribution of acute myocardial infarction and spatial analysis of cardiac care contributes significantly to improving health care interventions focusing on creative, novel initiatives (SEGHIERI, C. et al. 2019).
The main aim of this study is to analyse the spatial aspects of mortality of acute myocardial infarction (AMI) and determine the pattern of cardiac care regarding AMI geographical distribution in Hungary at microregional level. We assumed that spatial accessibility to cardiac care services would vary considerably among micro-regional units. On the other hand, micro-regional units with relatively better availability do not show up better accessibility as well. The specific objectives of this study are as follows:

1. to examine the potential geographical accessibility to cardiac care services across Hungarian micro-regions to identify underservices or poorly served geographical locations;

2. to investigate the differences between spatial characteristics of availability and accessibility;

3. to unfold the role of decision-making in the association of poor accessibility with shortage of health care services.

\section{Theoretical background: in the light of accessibility, availability and spatiality}

Access to health care is generally defined as access to a health service or a health provider, thus, defined as the opportunity with which consumers or communities are able to use appropriate services in proportion to their needs (DANiels, N. 1982; WhiteheAd, M. 1992). It is also defined as the use of health care, qualified by need for care (WATERs, H.R. 2000). Here, access may be conceived as the interface between potential users and health care resources, and would be influenced by characteristics of those who supply as well as those who utilise the services (Penchansky, R. and Thomas, W.J. 1981). It can describe potential users' ability to use health care services when and where they are needed in time and in space (ADAY, L.A. and Andersen, R.A. 1974). Availability can help to define the supply of services in relation to needs - whether there are adequate services to meet the healthcare needs (PENCHANSKy, R. and Thomas, W.J. 1981). 
There is a growing body of literature devoted to measuring and understanding geographical patterns of health care as well as health outcomes (CROMLEY, E.K. and McLafferty, S.L. 2011; Skinner, J. 2012). According to Penchansky, R. and Thomas, W.J. (1981) accessibility refers to the geographic availability to health care such as travel distance, time and cost (e.g. affordability of transportation). Both accessibility and availability refer to the spatial interaction between the geographical locations of health care services and population in need (YE, H. 2016). These constructs such as accessibility, availability, spatiality as geographical locations, thus, should be considered as interrelated. Access to health care, especially when used to reflect on health inequalities, should look at the resource allocation in relation to social and health needs as well as looking at geographical distribution of services linked to measures of needs and access (Braveman, P.A. 2003; Levesque, J.F. et al. 2013). Therefore, it is necessary to take into account spatial factors (e.g. geographical location, travel distance) as well as non-spatial factors (e.g. socio-economic status, gender, age) simultaneously, which are interrelated to each other and influence as critical barriers access to health care. The term spatial accessibility is used to refer to the combination of availability, acceptability, appropriateness, affordability of health demand and supply (Gulliford, M. et al. 2002; SAmuels, G. 2005; SHAH, T.I. et al. 2016). In addition to differences in patients' needs, spatial accessibility may be due to characteristics related to the health care system (demand and supply drivers), including the volume and distribution of human, physical and financial resources (Brezzi, M. and Luongo, P. 2016).

It is clear that health care resources are not evenly distributed over space. There are significant differences between urban and rural areas, and even in cities socio-economically disadvantaged neighbourhoods tend to have relatively poor access to health care (McIntyre, D. et al. 2009; Wilkinson, R. and Pickett, K. 2010; Marmot, M. 2015). While many study have focused on increasing accessibility problems among countries and within a country, there is hardly any research on access to health care services on the local level.

Many researches have demonstrated that increased travel distance to health care services resulted in decreased utilization of those services and therefore increased health inequalities (Sibley, L.M. and Glazier, R.H. 2009). Other studies also confirm that the supply of health care service may influence access and use. A better supply of health care in a neighbourhood guarantees reduced travel distances, which encourages more frequent visits and helps patients maintaining better health. For example, Andersen, R.M. (1995) found a positive correlation between the number of federally qualified health centres available and the likelihood of having a usual source of care. Thus, the disparity in the geographic distribution of health care services is of great concern ( $\mathrm{Y}_{\mathrm{E}}, \mathrm{H}$. 2016).

Accessibility of health care services is a key dimension in health inequality. Here the concept of 'health care access' is inherently multi-dimensional integrating both spatial and non-spatial factors. It is also linked to the theory of fundamental causes: the consequences of social stratification and structural inequalities can result health inequalities and not exposure to intermediary risk factors (Link, B.G. and Phelan, J. 1995).

\section{Data and methods}

In the study we used a systematic approach to identify socio-spatial consequences of policy interventions aimed to improve accessibility in the cardiac care of acute myocardial infarction of Hungary.

Our approach followed the guidance of explanatory sequential design in mixed methods (TAriq, S. and Woodman, J. 2013; Wisdom, J. and Creswell, J.W. 2013). We collected qualitative data in two steps to test quantitative findings with the following aims (Figure 1):

1. the aim of an initial quantitative analysis phase was to measure socio-spatial inequali- 
ties of mortality data at local level (as microregional units) in acute myocardial infarction, followed by

2. a qualitative data collection phase built directly on the results of the quantitative phase with the aim of studying personal experiences of local health care stakeholders and national health policy-makers on accessibility and availability of cardiac care.

In this way, the quantitative results have been explained in more detail through the qualitative data.

The primary objective of our quantitative analysis was to create a typical spatial framework of selecting socio-spatial variables and to explore spatial patterns in mortality of Acute Myocardial Infarction (AMI) at micro-regional level. The complex methodology of Exploratory Spatial Data Analysis (ESDA) was used to select the appropriate quantitative ways to analysis the nature of the spatial pattern of AMI mortality data. Using the ESDA tool allowed us to gain a deeper understanding of the connection between spatial distribution of AMI mortality data and different socio-spatial variables (e.g. Ord, J.K. and Getis, A. 1995; Kelejian, H.H. and PRuchA, I.R. 2010):

Principal Component Analysis (PCA): the method is a structure exploration method that is often used to create socio-economic indicators. The aim of PCA is to explore the relationships between several indicators, and join them in one or more factors. With the

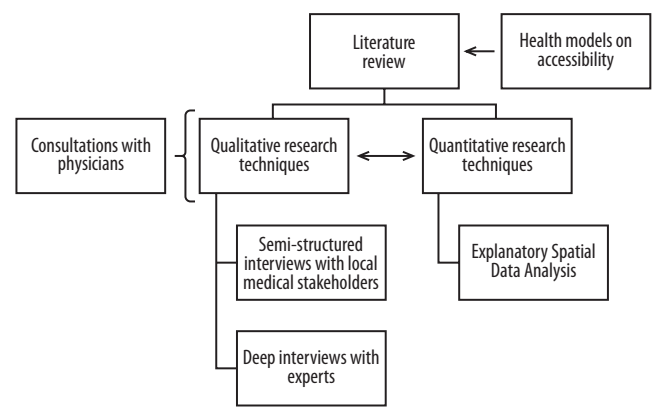

Fig. 1. Using explanatory sequential design in mixed methods
PCA we join six socio-economic indicators into a deprivation factor, applying Varimax rotation. The magnitude of the factor value shows the degree of deprivation.

Application of Exploratory Spatial Data Analysis (ESDA): Spatial Regression Analysis: if spatial dependence can also be experienced in case of analysed variables, the traditional estimation techniques (e.g. OLS: Ordinary Least Squares) cannot be applied. However, it is always necessary to use the results of OLS as a reference value. The examination of spatial dependence was done with Spatial Durbin Model (SDM).

a) Ordinary Least Squares method - OLS:

$$
y=X \beta+\varepsilon
$$

b) Spatial Durbin Model - SDM:

$$
y=X \beta+p W y+W X \theta+\varepsilon
$$

Explanation of the formulas: $y$ is the vector of the values of the dependent variables, $X$ is the vector of the values of the independent variables, $\beta$ is the parameter vector for these explanatory variables, and $\varepsilon$ is a vector of independent error probabilities with the same probability distribution. $W$ is spatial weight matrix, $\rho$ is spatial autoregressive coefficient, $\theta$ is the parameter for spatially lagged values of explanatory variables. In this case, $W$ as spatial weight matrix is based on queen matrix with first order of contiguity. It means, districts are neighbours of each other if their have common border. SDM is useful, because it defines the neighbouring values of result variables as well as explanatory variables which points to the exact existence of spatial interactions and neighbourhood effects.

Autoregressive coefficient cannot be applied directly in SDM rather than in OLS, because there are direct and indirect effects (LeSAge, J. and PAcE, R.K. 2009). Direct effects show the effect of explanatory variables for the given geographical location. Indirect show the spatial effect of explanatory variables as an 'neighbourhood effect' according to neighbouring matrix (ELHORST, J.P. 2014). 
Likelihood ratio tests autoregressive coefficient reliability, the Breusch-Pagan test is for heteroskedasticity, and the Multicollinearity Condition Number tests the co-movement of the involved explanatory variables, the redundancy of the dataset. The performance of the regression equations was evaluated by the R2, the pseudo R2, the Akaike information criterion and log likelihood.

Convergence tests: Change of AMI mortality was calculated with the help of absolute and conditional $\beta$-convergence. According to the absolute $\beta$-convergence model, there is a negative relationship between the initial level of a variable and its rate of growth (e.g. AMI mortality), and, thus, the individual regions converge towards a common equilibrium (Barro, R.J. and Sala-i-Martin, X. 1990; Goli, S. et al. 2019). According to the conditional convergence, growth rates are influenced not only by the initial state but also by other factors, thus, the equilibrium state may vary depending on these factors (JANSSEN, F. et al. 2016).

a) Absolute convergence:

$$
\Delta \ln y_{i}=\alpha+\beta \ln y_{i, 0}+\varepsilon,
$$

where $\alpha$ and $\beta$ are the unknown parameters in the equation, $\varepsilon$ represents the effect of the random factor.

b) Conditional convergence:

$$
\Delta \ln y_{i}=\alpha+\beta \ln y_{i, 0}+y z_{i, 0}+\varepsilon,
$$

where the new parameter $(z)$ to the right of the equation indicates different characteristics of the districts (e.g. deprivation).

Spatial autocorrelation: we analysed spatial concentrations of AMI deaths and their changes with the help of this method. Hot spot analysis and the use of the Getis-Ord $\left(G_{i}^{*}\right)$ statistic identified statistically significant hot and cold spots (clusters).

$$
G_{i}^{*}=\frac{\sum_{j=1}^{M} w_{i j} d_{j}}{\sqrt{\frac{\sum_{j=1}^{M} d_{j}^{2}}{M}} \sqrt{\frac{M \sum_{j=1}^{M} w_{i j}^{2}-\left(\sum_{j=1}^{M} w_{i j}\right)^{2}}{M-1}}}
$$

Explanation of the formula: $M$ is the number of area units examined, $w_{i j}$ stands for the $i$ and $j$ elements of the neighbourhood matrix, the numerator indicates the sum of the $d_{i}$ values weighted by the $i$-th row of the neighbourhood matrix, and the values in the denominator serve for standardization (Getis, A and Ord, J.K. 1992). Calculations and visualization of the results were realized with SPSS for Windows 25, ArcMap 10.5 and GeoDaSpace and R Program.

Acute myocardial infarction statistics were based on International Classification of Diseases $11^{\text {th }}$ Revision (ICD) such as I21-I23 diagnosis codes. AMI mortality data was based on standardized death rate (SDR) by gender per 100,000 between 2005 and 2015 at microregional level (LAU 1). ICD diagnosis codes mean the following:

I21 - Case of acute myocardial infarction;

I22 - Subsequent case of AMI;

I23 - Certain current complications following acute myocardial infarction (within the 28 days period).

Standardized death rate per 100,000 is officially publishing by gender, so it can be used only in gender aspect. Standardized death rate of AMI per 100,000 can be used only by gender, because arithmetic average cannot be calculated from male and female SDR. AMI SDR data base is based on 30 days mortality rates.

The number of micro-regional units in Hungary was 174 without 23 districts of Budapest. We did not consider Budapest's districts in our analysis, because health care services have better availability in the city which could have distorted the final results. Due to the small number and annual variation of district-level mortality, two periods and four-year averages were used in the convergence analyses (between 2005 and 2008, and between 2012 and 2015). That is, the quantitative part consists of a regression analysis based on ESDA on micro-regional data from the countryside over two multiyear periods (sample size of $2 \times 175$ ).

AMI mortality data contain only demographic variables (gender, age), but there is no further information on patient's socio- 
economic circumstances. In our analysis, and index of deprivation was used to give comprehensive information about connection between AMI mortality data and spatial distribution of poverty at micro-regional level. This variable was included as a control factor in the convergence analyses, because some authors correlate cardiovascular mortality with distance to a health care service (e.g. catheter centre) as an explanatory variable and a compound measure of poverty ('deprivation') as a control variable (e.g. NAGY, Cs. et al. 2011; Boruzs, K. et al. 2018). In the regressions, deprivation allows for some additional spatial correlation between the observations. The deprivation index adjusted to the socio-economic characteristics of AMI patients was operationalised by Koós, B. (2015) using the following indicators:

- Ageing-index (proportion of population under 15 against $60+$ within population);

- Ratio of households with only unemployed and inactive person(s);

- Unemployment rate (proportion in economically active population);

- Personal income tax per capita;

- Ratio of apartments without comfort;

- Ratio of those with only secondary education.

Availability was defined as spatial/geographical distance from different health care services (e.g. cardiac catheterization). In this case, distance was measured by road in $\mathrm{km}$ between residence (geographical centre of the given district) and geographical location of the examined health care service.

Access to health care was defined as access to catheter centre (PCI centre) in statistical analysis, because this type of intervention means a modern cardiological care which can increase short-term survival chance. This is the main reason why we interpret the role of catheter centre in AMI mortality as the distance between residence and catheter centre. On the other hand, access to health care was also defined as access to rehabilitation care as well as primary health care in the semi-structured interviews to analyse the personal opinion of respondents. Access to rehabilitation care as well as primary health care cannot be measured in statistical analysis, because of lack of suitable spatial data. The official source of data was the Hungarian Central Statistical Office and its Population Census database (2011), and the National Institute for Health Development.

The initial quantitative analysis helped us:

1. to select the local case study areas for qualitative research,

2. to work out the scopes and structure of interviews which could complete the results of the quantitative analysis,

3. to elaborate the structure of semi-structured interviews with local health care stakeholders (on the one hand with local health care professionals/workers and on the another with patients diagnosed with AMI),

4. to select common guidelines for the two types of semi-structured interviews in order to be able to compare their results,

5. to elaborate the pattern of expert interviews with national policy-makers,

6. to work out general criteria to evaluate and synthesize experiences of the interviews with special focus on the role of geographical distance in accessibility.

The local case study area was one of Hungary's counties called Békés. We have chosen this county because results of our statistical analysis confirmed the paradoxical health situation of this county according to AMI mortality as well as other health indicators. The initial point of the analysis was that the new centre of cardiac catheterization was inaugurated in 2013 in the county, however, a slight worsening in AMI mortality could be experienced in the following few years. AMI mortality rate has also been high in both genders compared to other Hungarian counties. Moreover, high rate of AMI mortality reflects the general worse mortality structure of the county. The average life expectancy at birth in Békés county was one year less than the country average in 2019. In this county 55 per cent of total mortality is due to cardiovascular diseases, which is also higher than the national average (BEKE, Sz. 2019).

Semi-structured interviews with local health care stakeholders were prepared in 
two steps between April and June in 2018. The primary aim was to examine personal experiences of individuals on barriers in access to cardiac care services. For instance, determinative individual (e.g. health behaviour) and institutional (e.g. supply standards) factors which had effects on access to cardiac care.

Firstly, altogether 24 semi-structured interviews were prepared with relevant cardiac care stakeholders such as cardiologist, internist, ambulance doctor, nurse, nutritionist, psychologist, physiotherapist etc. These interviews provided insights about the professional features of organizing cardiac care at local level. Secondly, altogether 29 semi-structured interviews were made with patients who had at least once acute myocardial infarction in their lifetime. Questions during the semi-structured interviews were addressed to define local difficulties and opportunities in access to cardiac care services from the patients' point of view. All questions were classified according to different phases of cardiac care such as pre-hospital, hospitalization and post-hospital care.

After the transcription of semi-structured interviews, the personal experiences were synthesized to explain the role of geographical distance in accessibility. These synthesized experiences provided the basis for expert interviews which aimed to unfold the role of national health policy in improving accessibility. Altogether 21 expert interviews were conducted with policy-makers, national health care providers and health policy advisers between February and July in 2019. The aim of expert interviews was to evaluate the effects of health policies in terms of improving the conditions of accessibility. The expertise of interviewees' skills included all level of health care, health promotion and disease management as well.

\section{Research results: spatial inequality in the care of Acute Myocardial Infarction (AMI)}

The number of deaths caused by diseases of circulatory system was 64,695 , the number of deaths caused by ischaemic heart diseases was 31,828 , while mortality caused by AMI was 5,758 in Hungary in 2018 (Hungarian Myocardial Infarction Registry 2019). In the past years, AMI deaths generally caused nearly one fifth of all circulatory system mortality. Hospital treatment due to AMI was 15.082 in 2018, 38 per cent of them was ending with deaths (Jánosi, A. 2019). The main problem in Hungary is the lack of significant improvement in one-year mortality in contrast to the 30 days mortality following AMI (Mérték Review, 2017).

The decrease of AMI (acute myocardial infarction) caused mortality rate started from the mid-2000s in Hungary, and between 2005 and 2015, mortality rate halved. The improvement affected both genders, and it was greater among men, however, still nearly twice as many men get a heart attack than women (Uzzoli, A. et al. 2019a). Frequency of myocardial infarction is highest among elderly (60+), though in recent years there was a slight increase in younger age groups as well (e.g. over 40 years).

One explanation for the improving mortality situation in Hungary is that due to infrastructural developments, from the mid-2000s new PCI centres (centre for catheterization) have been created in the country, and the capacity of already existing centres has been increased, therefore, accessibility to care has also been improved (KIss, A. et al. 2019). Through health investment, the proportion of patients receiving cardiac catheter care nearly doubled between 2005 and 2015, which improved short-term survival chances.

\section{Results of the statistical analysis}

We applied quantitative methods to examine the potential geographical accessibility to cardiac care services across Hungarian micro-regional units to identify underservices or poorly served geographical locations.

In the principal component analysis, the deprivation index calculation resulted in a principal component. Indicators that interpret deprivation are suitable for principal component analysis, showing adequate match and information density (Table 1). 
Table 1. The main statistical features of applied deprivation principal component

\begin{tabular}{l|c|c}
\hline \multicolumn{1}{c|}{ Indicators } & Communalities & Component \\
\hline Unemployment rate & 0.877 & 0.937 \\
Proportion of households with only unemployed and out-of-work person & 0.844 & 0.919 \\
Proportion of apartments without comfort & 0.773 & 0.879 \\
Proportion of those with only secondary education & 0.752 & -0.867 \\
Personal income tax per capita & 0.736 & -0.858 \\
Proportion of population under 15 on population over the age of 60 per 100 capita & 0.268 & 0.518 \\
\hline Kaiser-Meyer-Olkin Measure & \multicolumn{2}{|c}{0.780} \\
Bartlett test significance & \multicolumn{2}{|c}{0.000} \\
Eigenvalue & \multicolumn{2}{|c}{4.251} \\
Cumulative variance & \multicolumn{2}{|c}{70.854} \\
\hline
\end{tabular}

According to our indicators, in the districts with high unemployment rate the proportion of households with only unemployed persons and the share of homes without comfort are higher, just like the proportion of the population under the age of 15 per population over 60 per 100 persons. Thus, a higher principal component value is accompanied by a higher value of the deprivation index.

The geographical pattern of the deprivation index presents the most important features of socio-spatial inequalities within Hungary that are characterized by Western-Eastern and Centre-Periphery relations (Figure 2). The spatial pattern of AMI mortality shows many similarities. As Figure 3 shows higher AMI mortality rates are recorded in areas that are most affected by deprivation.

There is a poor to moderate positive but strongly significant relationship between AMI mortality rate and deprivation index $(r=+0.352, p<0.000)$. Deprivation and AMI mortality is high in the eastern part of the country, mainly in border areas. However, in the economically most advanced Budapest metropolitan region low deprivation comes also with high AMI mortality. In the southwestern part of the country the level of deprivation is relatively high, but AMI mortality is low. Significant spatial dependence can be observed for both investigated indicators caused by neighbourhood effects.

Only the relevant spatial regression results are reported in Tables 2 and 3. Spatial All regression calculation results indicate that there is a definite convergence. This phenomenon applies to all models both in the absolute (OLS model 1) supplemented by spatiality (SDM model 1) and in the conditional (OLS model 2 and SDM model 3) convergence equations supplemented with structural features (Tables 2 and 3). It is based on negative regression coefficient of initial AMI mortality. It means, higher initial AMI mortality goes together with lower level of increasing with the result of more significant decreasing of AMI mortality in the examined period. The reverse is also true: lower initial AMI mortality goes together with higher level of increasing with the result of less significant decreasing of AMI mortality in the examined period.

The deprivation index behaves significantly in these models, with the control of other variables the phenomenon of deprivation increases the mortality rate of infarction. The distance from cardiac catheter centres is a relevant control factor in regression analysis. The longer distant is a district from a PCI cardiac catheter centre, the less convergence it is.

It is important to emphasize that both in absolute and in conditional convergence analysis the spatial lag of AMI change is relevant $(p)$, that is, the neighbouring values of the dependent variable affect the change of the AMI mortality in each district. That is, the neighbourhood effect is decisive in the spatial inequalities in AMI mortality.

Table 3 exactly shows the effects of explanatory variables. Based on SDM 1, in those dis- 


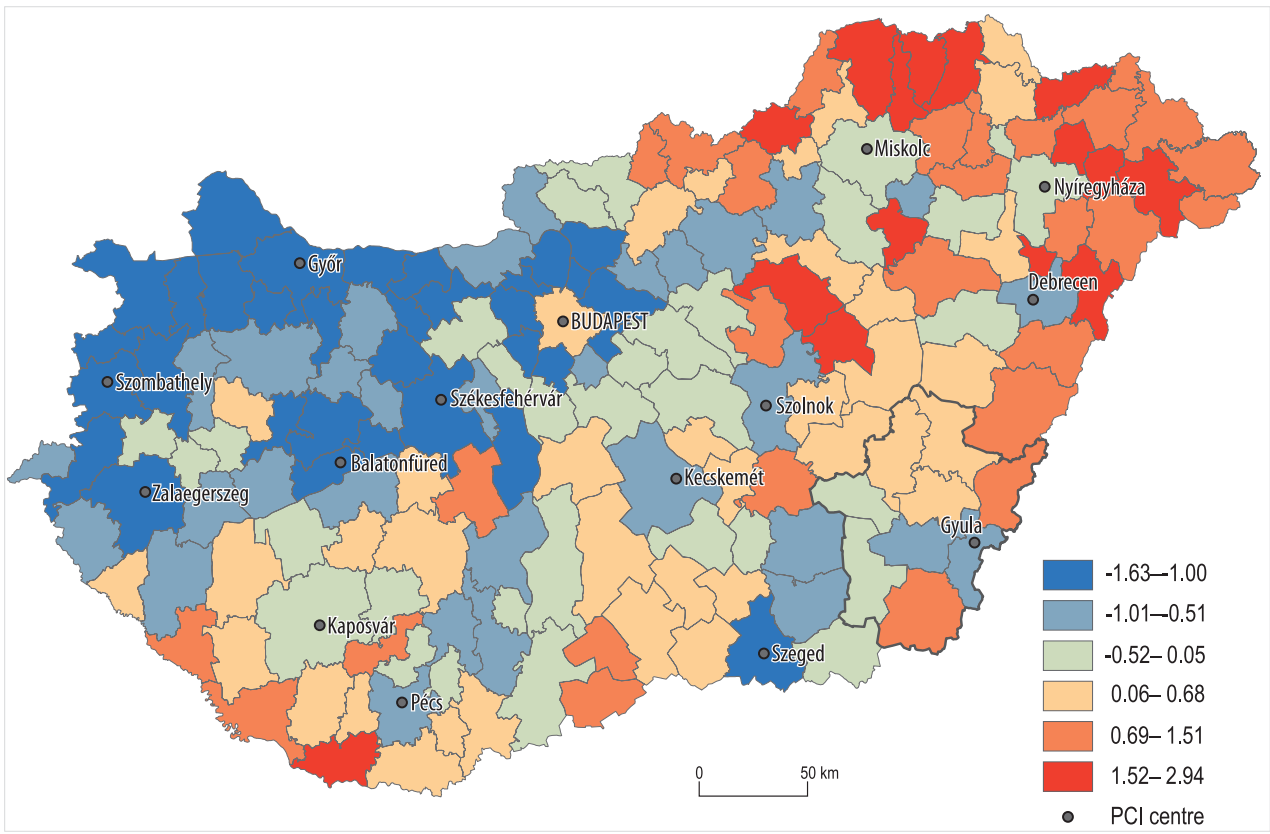

Fig. 2. The spatial pattern of deprivation index at micro-regional level in Hungary (2012-2015).

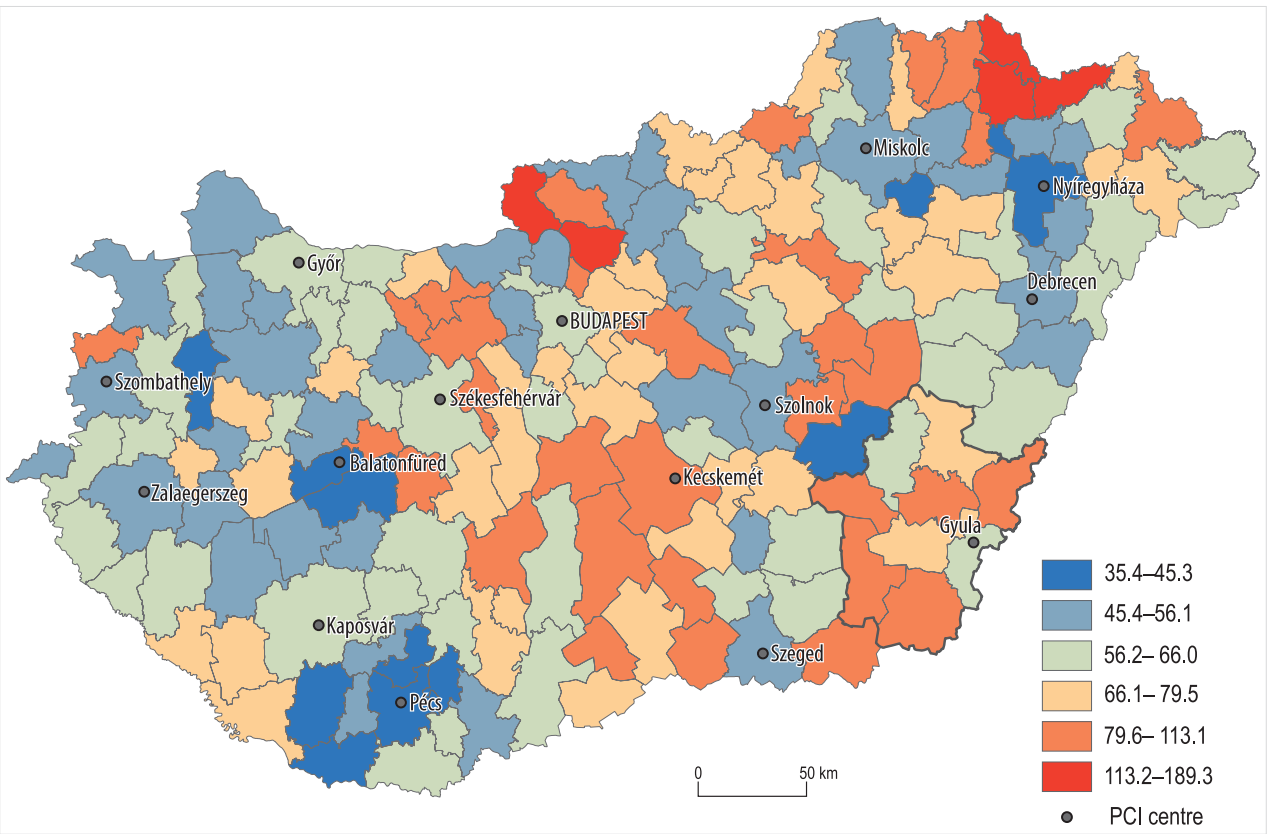

Fig. 3. Standardised death rate of acute myocardial infarction per 100,000 at micro-regional level in Hungary (entire population, 2012-2015). 
Table 2. Absolute and conditional B-convergence studies of AMI mortality

\begin{tabular}{|c|c|c|c|c|}
\hline Indicator & OLS (1) & SDM (1) & OLS (2) & SDM (2) \\
\hline Initial AMI SDR & $\begin{array}{l}-0.210^{* * *} \\
(0.044)\end{array}$ & $\begin{array}{l}-0.184^{* * *} \\
(0.042)\end{array}$ & $\begin{array}{l}-0.200^{* * *} \\
(0.044)\end{array}$ & $\begin{array}{l}-0.174^{* * *} \\
(0.042)\end{array}$ \\
\hline Deprivation & - & - & $\begin{array}{c}0.042^{*} \\
(0.024)\end{array}$ & $\begin{array}{r}0.048^{*} \\
(0.029)\end{array}$ \\
\hline Distance & - & - & $\begin{array}{c}0.002 \\
(0.001)\end{array}$ & $\begin{array}{c}0.000 \\
(0.002)\end{array}$ \\
\hline $\mathrm{p}$ & - & $\begin{array}{l}0.272^{* * *} \\
(0.105) \\
\end{array}$ & - & $\begin{array}{l}0.220^{* * * *} \\
(0.108)\end{array}$ \\
\hline$\Theta$ initial AMI SDR & - & $\begin{array}{l}-0.199^{*} \\
(0.107)\end{array}$ & - & $\begin{array}{l}-0.233^{* * *} \\
(0.107)\end{array}$ \\
\hline$\Theta$ deprivation & - & - & - & $\begin{array}{l}-0.024 \\
(0.041)\end{array}$ \\
\hline$\Theta$ distance & - & - & - & $\begin{array}{r}0.004^{*} \\
(0.002) \\
\end{array}$ \\
\hline Constant & $\begin{array}{l}0.570^{* * *} \\
(0.213)\end{array}$ & $\begin{array}{l}1.527^{* * *} \\
(0.525)\end{array}$ & $\begin{array}{l}0.438^{* *} \\
(0.216)\end{array}$ & $\begin{array}{l}1.470^{* * *} \\
(0.522)\end{array}$ \\
\hline Observations & \multicolumn{4}{|c|}{174} \\
\hline AIC & 25.370 & 20.996 & 22.951 & 21.924 \\
\hline $\log \mathrm{L}$ & -8.685 & -1.498 & -5.476 & 2.038 \\
\hline R2 Adjusted & 0.186 & 0.275 & 0.229 & 0.349 \\
\hline Moran test / LM residual auto. test & $0.134^{* * *}$ & 0.048 & $0.121^{* *}$ & 0.858 \\
\hline Breusch-Pagan test & $8.099^{*}$ & $14.258^{*}$ & 12.610 & 17.980 \\
\hline
\end{tabular}

Explanation: Estimation of all models is based on row standardized queen matrix with first order of contiguity. Standard errors are in parenthesis. $p=$ spatial autoregressive coefficient; $\Theta=$ the parameter for spatially lagged values of explanatory variables; Moran test and LM residual auto. test $=$ for spatial autocorrelation of standard errors; Breusch-Pagan test is for hetero-skedasticity. ${ }^{*}$ Significant on $0.10 \%,{ }^{* *}$ on $0.05 \%,{ }^{* * *}$ on $0.01 \%$.

Table 3. Direct and indirect effects of Spatial Durbin Models

\begin{tabular}{l|c|l|l}
\hline \multicolumn{1}{c|}{ Indicator } & Direct & Indirect & Total \\
\hline \multicolumn{4}{|c}{ SDM (1) } \\
\hline Initial AMI SDR & $-0.198^{* * *}$ & $-0.327^{* *}$ & $-0.525^{* * *}$ \\
\hline \multicolumn{4}{c}{ SDM (2) } \\
\hline Initial AMI SDR & $-0.186^{* * *}$ & $-0.336^{* * *}$ & $-0.521^{* * *}$ \\
\hline Deprivation & $0.048^{*}$ & -0.017 & 0.031 \\
\hline Distance & 0.000 & $0.005^{*}$ & $0.004^{* *}$ \\
\hline
\end{tabular}

Explanation: Standard errors are in parenthesis. *Significant on $0.10 \%,{ }^{* *}$ on $0.05 \%,{ }^{* * *}$ on $0.01 \%$.

tricts where AMI mortality is high there is more significant improvement, which means that convergence is existing. The results of SDM 1 also present that AMI mortality is significant in neighbouring districts. It means in the vicinity of those districts where AMI mortality is higher the convergence is also more significant. SDM 1 highlights that dis- tricts with similar AMI mortality rates are spatially concentrated, and the convergence is appeared more concentrated in Hungary. SDM 2 presents these spatial effects more sophisticated. One of main results shows the significant spatial concentration in the initial of AMI mortality as well as in its changes. Other result shows that deprivation has only local effect on AMI mortality and it has not got spatial effect on neighbouring districts. It is also valid for the role of distance from cardiac catheter centres, because it has got only indirect spatial effect on AMI mortality rates (see Table 3 Total column). The fact is that initial AMI mortality rates of districts influence the convergence in Hungary.

The application of spatial autocorrelation method proved that spatiality is primarily an explanatory factor for spatial inequalities in AMI mortality through neighbourhood ef- 
fects. The role of distance is more closely related to the geographical location of cardiac catheter centres and vacant GP services. It is also important to emphasize that traditional socio-economical peripheries function in opposite directions when spatially distributed. In the disadvantaged south-western part of the country it can be observed that in the case of men in the early period of survey cold spot neighbourhoods became hot spot neighbourhoods that is there was a deterioration in the situation between 2005 and 2008, and 2012 and 2015 (Figure 4). In the underdeveloped northeastern part of the country, the initial high hot spot AMI mortality for women comes along with a very favourable trend in the future. For both genders in the most developed capital agglomeration unfavourable-high AMI mortality rate- neighbourhood spatial extension occurred between 2005 and 2008, and 2012 and 2015. The unfavourable change in female AMI mortality in the south-eastern neighbourhood is striking: that is the reason why this region (Békés county) has become the pilot area of the qualitative case study (Figure 5).

According to Voss, P.R. et al. (2006), the explanation of spatiality can stem from several reasons. On the one hand, individuals, households, communities are in interaction with one another, influence each other. On the other hand, according to grouping forces, groups with similar social status choose to live close to one another. Thirdly, according to grouping responses, individuals with similar characteristics react to external forces in a similar way.

\section{Results of semi-structured interviews with stakeholders of local health care system}

We conducted semi-structured interviews with patients and health care professionals at the local level to investigate the differences between spatial contexts of availability and accessibility.

The main questions of semi-structured interviews were the following:

- What spatial characteristics help or hinder access to health care at local level?
- How are patient journeys organized in infarction care at the local level, and what possibilities, and/or barriers do they mean for the patients?

- What is the role of availability at local level in access to cardiac care of infarction?

Based on subjective opinion of interviews with health care professionals and patients, the paradoxical misperception of availability and accessibility could be found. We discuss here only those findings that relate to the evaluation of this paradoxical situation by emphasizing the role of spatial/geographical factors.

Geographical proximity does not necessarily mean more favourable conditions in accessibility. Interviews confirmed that availability is a primary influencing factor in accessibility conditions, however, its supporting or barrier role in accessibility manifests itself diversely in the different stages of infarction care. The supporting or barrier effect of availability primarily prevails in geographical distance.

In the stage of pre-hospital care, the spatial optimization of emergency care resulted in the improvement of availability on local level. Nevertheless, it does not involve the improvement in conditions of accessibility, because due to the low level of patients' health literacy, they delay for a long time asking for medical assistance after the first symptoms of infarction.

Hospitalization contributes differently to the role of availability in the improvement or blocking of accessibility. Acute care (cardiac catheter care) is centralized, it means a clear patient pathway, which is based on a horizontal professional cooperation (between the rescue/emergency unit and cardiac catheter centre). Consequently, the establishment of cardiac catheter centre as an infrastructural investment improved both availability and accessibility on local level. It mainly means a short-term (30 days) improvement of survival chances. In contrast, in hospital rehabilitation care availability appears to be as a barrier factor for accessibility. Interviews made with health care professionals indicated, that on the one hand, approximately 30 per cent of 


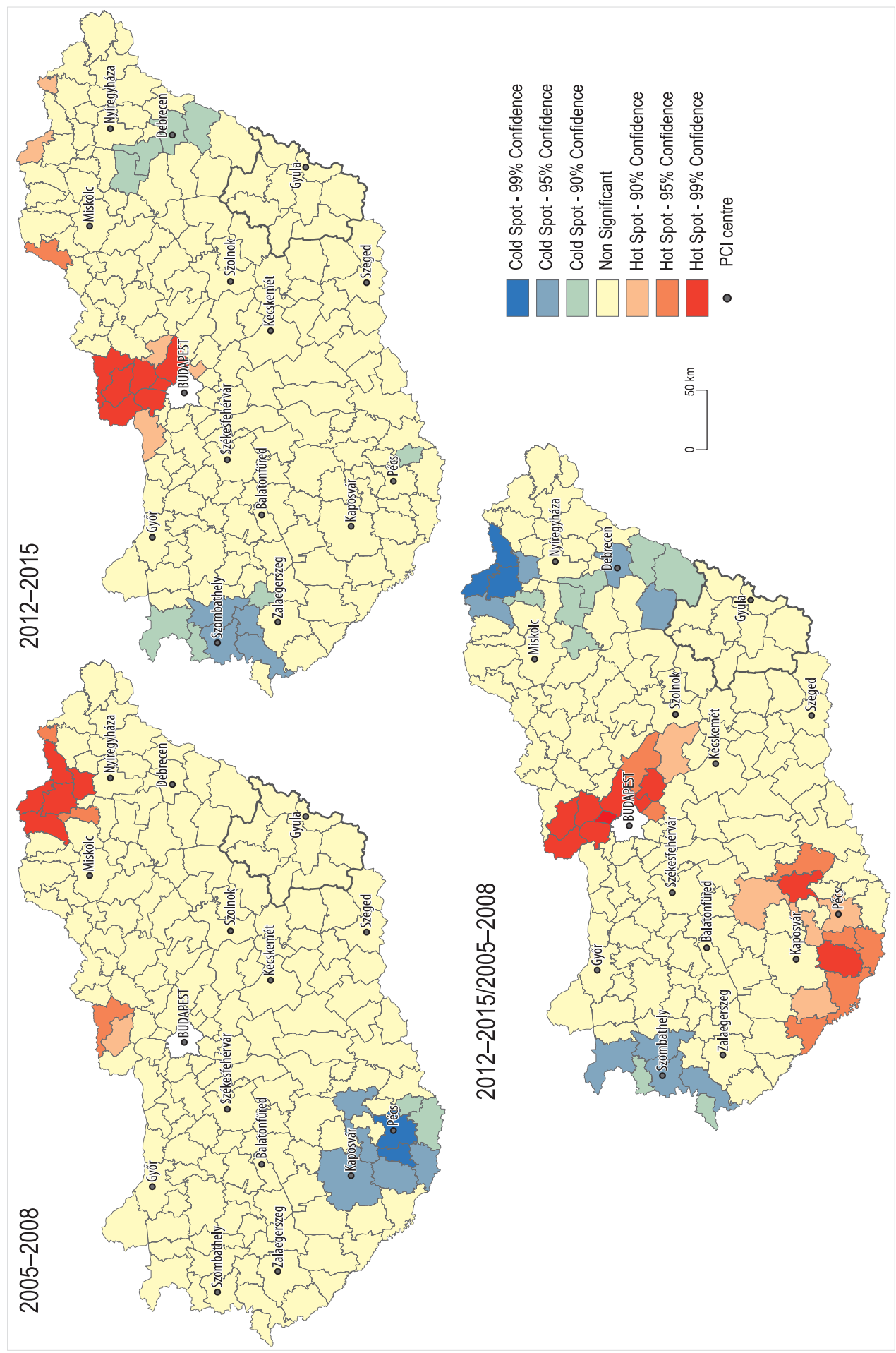

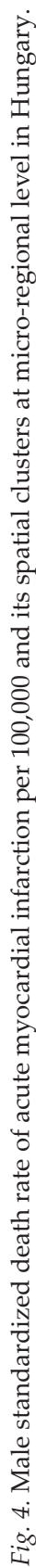




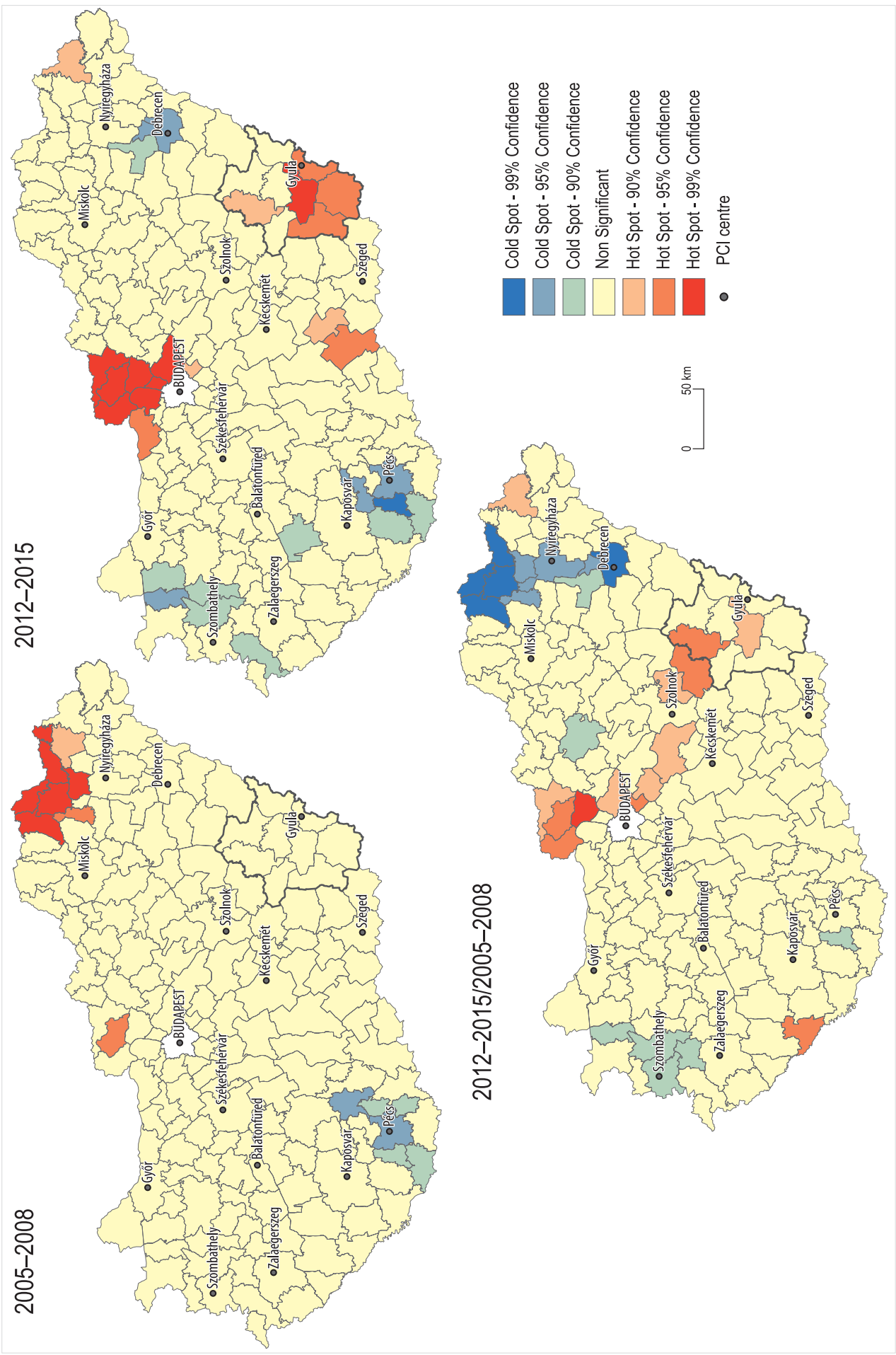


patiens receive rehabilitation after infarction, and on the other hand, despite the inauguration of the local new cardiac catheter centre, there was an increase in the one-year mortality rate in recent years. Patient interviews confirmed that many patients refused rehabilitation in order to return to work faster, therefore, those residing nearer to the rehabilitation centre will not use health care service.

In post-hospital care, the role of the general practitioner and specialist care provision is determinative. Both provision levels are seriously affected by the lack of capacity (unfilled general practitioner's service, lack of specialist). Therefore, there is frequently no close professional cooperation between neighbouring areas (lack of integrated health care). Due to the poor road conditions, insufficient public transport, and the lack of resources (own car), patients can hardly reach neighbouring districts' health care. It means a long travelling time and/or higher cost to them.

In addition, the efficiency of rehabilitation and post-rehabilitation care depends on patient education and on health literacy. Especially in peripheral areas, for those living in small villages, the conditions for prevention and care for a healthy lifestyle are less insured (near-patient services). The long-term survival chances after infarction depend on the professional content of medical instructions, the willingness to take medication, and the success of lifestyle change. It was also mentioned in interviews that responsibility of local health care professionals such as general practitioners and specialists is significant in long-term survival chance. The lack of local opportunities to support this latter, their limited availability is determinative in urban-rural proportion. Local conditions, social norms and habits of healthy lifestyle are different in cities and villages. Given the significant socio-economic inequalities in Hungary the importance of health behaviour is one of determinants in health outcomes.

According to the unanimous opinion of the interviewed health care professionals and patients, the factors that most support accessibility are related to the improvement of avail- ability, the infrastructural investments, and to the development of patient-centred health care (Uzzoli, A. et al. 2019b). It was also unanimously stated that factors that are the main barrier to accessibility are distance, lack of financial resources, difficulties of lifestyle change, weak compliance, low level of health knowledge and lack of capacities (Figure 6).

\section{Travelling distance $\begin{gathered}\text { Bordeline location } \\ \text { Compliance }\end{gathered}$ \\ Health behaviour Geographical distance Material resouling time Capacity accessibitity Healthy lifestyle Health literacy}

Fig. 6. Barriers in access to cardiac care in Hungary based on semi-structured interviews, 2018.

\section{Results of the in-depth interviews with experts}

We made in-depth interviews with experts to find out the role of decision-making in the association of poor accessibility with shortage of health care services.

The main group of questions of interviews were the following:

- What contradictions have emerged in the operation, organization and financing of the Hungarian health care system after the change of regime?

- What are the main causes and factors of socio-spatial disparities in health inequalities in Hungary?

- What is the role of decision-making in reducing health inequalities and improving accessibility in Hungary?

In-depth interviews with experts highlighted the paradoxical role of availability and accessibility in policy making. Accessibility barriers to health care are linked mainly to financial, availability and socio-cultural barriers. Increasing lack of capacity and workforce in healthcare system has led to new types of inequalities in 
Hungary, resulting in a widening health gap between the upper and lower deciles of society.

The place of residence in itself is one of the relevant factors of health inequalities and conditions of accessibility: its explanatory power multiplies with existing socio-economic and socio-cultural disadvantages. It is partly a matter of value choice that in health policy making to what extent cost-effectiveness and/or social justice efforts are pursued.

Interventions to reduce health inequalities and improve accessibility should focus on areas where the greatest social benefits (i.e. health gains) can be achieved. Communitybased development and patient-centred care play a key role in rehabilitation, health promotion and disease prevention. However, in areas affected by deprivation, improving availability does not necessarily mean improving accessibility. In underprivileged areas 'social distance' is increasing between patients and health services because deprivation is a barrier factor to accessibility. In such cases, subjective evaluation of distance does not refer to physical availability, but rather to the conditions of accessibility worsened by social barriers.

\section{Conclusions}

In this study, we examined the spatial dimensions of availability and accessibility in health care provision. More specifically we analysed the connection between deprivation and mortality rate of AMI, while the role of availability and accessibility in mortality rate was identified according to spatial distribution of cardiac care services. We used different quantitative and qualitative research methods to determine the role of spatial factors (e.g. place of residence, geographical distance, physical availability etc.) in access to health care. We also wanted to shed light on the paradoxical situation between the objective and the subjective factors of availability and accessibility. Main research findings are the following:

- Geographical proximity does not necessarily mean better conditions in accessibility, and stronger professional cooperation between health services;

- Availability is more a determining factor in accessibility based on patients' opinions as statistical calculations have shown;

- According to the unanimous opinion of health care stakeholders (professionals and patients), the factors that most support accessibility are related to the improvement of availability, investments in infrastructure and the provision of patient-centred care. This finding is in agreement with a number of previous studies (BuzAI, G. 2013; Illés, S. and Gellérné LuKÁcs, É. 2016).

The subjective perception of the accessibility of health care institutions highlighted that patients' use of out-of-home services delays rehabilitation because of their long travel time and reduces their willingness to participate in long-term care.

Based on the regional distribution of AMI mortality and the availability and accessibility of features of infarction care, there is a lack of community-based developments in Hungarian strategic health plans. Improvements in accessibility have mainly affected acute cardiac care in recent years, but have also failed to improve access to rehabilitation care.

Our study also has some limitations. Based on in-patient care data, we were not able to compile a morbidity database that could have been comparable with mortality database. We could not make a difference between AMI STEMI and Non-STEMI cases in mortality statistics, although, it has significance in cardiac rehabilitation. In practice, there are some cases when the catheterization is not initiated due to other factors (comorbidity, age), and these cases are not discernible in statistics. Patients' socio-economic status could only be indirectly predicted from statistical data. Interviews with patients could not be extended to relatives, although they play a key role in the success of long-term lifestyle changes, i.e. in long-term survival chances. Despite these limitations, this study provides a methodologically complex perspective on examining accessibility with its spatial factors. 
Our findings also suggest that geographical aspects of health inequalities as well as access to health care should receive more attention in health development strategies. Geographical location similarly to geographical distance has primarily role in health inequalities as well as in accessibility.

Firstly, geographical concentration of health care institutions may influence availability with the result of complex disadvantages of peripheral regions.

Secondly, geographical distance has a relative role based on objective and subjective factors. Objectively, it should not appear as barrier in availability based on an optimal resource allocation. Subjectively, geographical location is at a longer distance from health care institutions means more barriers in accessibility and availability based on patients' evaluation.

Thirdly, the role of geographical distance seems to appear as a challenge for local population living in inner and geographical peripheries or in borderline areas. Fourthly, in peripheral regions with small villages hit by deprivation patient-centred health care - especially in prevention and health promotion as the part of primary health care - is missing or has many weaknesses.

Finally, typical spatial pattern of health inequalities in Hungary (Western-Eastern gradient, core-periphery relation) can influence regional distribution of material and human resources in health care.

Acknowledgements: This research was supported by the Hungarian Scientific Research Fund (OTKA) Grant Agreement No. K119574.

\section{REFERENCES}

AdAy, L.A. and Andersen, R.A. 1974. A framework for the study of access to medical care. Health Services Research 9. 208-220.

Alter, D.A., Naylor, C.D., Austin, P. and Tu, J.V. 1999. Effects of socioeconomic status on access to invasive cardiac procedures and on mortality after acute myocardial infarction. New England Journal of Medicine 341. (18): 1359-1367.

Andersen, R.M. 1995. Revisiting the behavioral model and access to medical care: does It matter? Journal of Health and Social Behavior 36. (1): 1-10.
Aso, S., Imamura, H., Sekiguchi, Y., Iwashita, T., Hirano, R., Ikeda, U. and Окамото, K. 2011. Incidence and mortality of acute myocardial infarction. A population-based study including patients with out-of-hospital cardiac arrest. International Heart Journal 52. (4): 197-202.

Barro, R.J. and SAla-I-Martin, X. 1990. Economic growth and convergence across the United States. Working Paper 3419. Cambridge, National Bureau of Economic Research.

BEKE, Sz. 2019. Early treatment of acute myocardial infarction and its regional differences in Békés county. DETUROPE - The Central European Journal of Regional Development and Tourism 11. (1): 182-195.

Braveman, P.A. 2003. Monitoring equity in health and healthcare: A conceptual framework. Journal of Health, Population and Nutrition 21. (3): 181-192.

Boruzs, K., Juhász, A., NAGY, C., Szabó, Z., JakovlJEviC, M., Bíró, K. and ÁdÁNY, R. 2018. High inequalities associated with socio-economic deprivation in cardiovascular disease burden and antihypertensive medication in Hungary. Frontiers in Pharmacology 9. 839. Doi: $10.3389 /$ fphar.2018.00839

Brezzi, M. and Luongo, P. 2016. Regional disparities in access to health care: A multilevel analysis in selected OECD countries. OECD Regional Development Working Papers 2016/04. Paris, OECD Publishing. Buchmueller, T.C., Jacobson, M. and Wold, C. 2006. How far to the hospital? The effect of hospital closures on access to care. Journal of Health Economics 25. 740-761.

BuzAI, G. 2013. Location-allocation models applied to urban public services. Spatial analysis of primary health care centres in the city of Luján, Argentina. Hungarian Geographical Bulletin 62. (4): 387-408.

Cromley, E.K. and McLafferty, S.L. 2011. GIS and Public Health. New York, Guilford Press.

DANIELs, N. 1982. Equity of access to health care: some conceptual and ethical issues. Milbank Memorial Fund Quarterly 60. 51-81.

Elhorst, J.P. 2014. Spatial Econometrics. Berlin, Springer.

Getis, A. and Ord, J.K. 1992. The analysis of spatial association by use of distance statistics. Geographical Analysis 24. (3): 189-206.

Goli, S., Swastika Chakravorty, M. and Rammohan, A. 2019. World health status 1950-2015: Converging or diverging. PLOS ONE 14. (3): e0213139. Available at https://doi.org/10.1371/journal.pone.0213139

Gulliford, M., Figueroa-Munoz, J., Morgan, M., Hughes, D., Gibson, B., Beech, R. and Hudson, M. 2002. What does 'access to health care' mean? Journal of Health Services Research and Policy 7. (3): 186-188.

Harper, K. and Armelagos, G. 2010. The changing disease-scape in the third epidemiological transition. International Journal of Environmental Research and Public Health 7. (2): 675-697. 
Hassan, A., Pearce, N.J., Mathers. J., Veugelers, P.J., Hirsch, G.M. and Cox, J.L. 2009. Improving cardiovascular outcomes in Nova Scotia investigators. The effect of place of residence on access to invasive cardiac services following acute myocardial infarction. The Canadian Journal of Cardiology 25. (4): 207-212.

Hungarian Myocardial Infarction Registry, 2019. Available at https://ir.kardio.hu/ir/fooldal

Illés, S. and Gellérné LukÁcs, É. 2016. Spatial characteristics of access of third-country citizens to the Hungarian public health care system. Hungarian Geographical Bulletin 65. (1): 71-80.

Janssen, F., van den Hende, A., de Beer, J. and van Wissen, L.J.G. 2016. Sigma and beta convergence in regional mortality: A case study of the Netherlands. Demographic Research 35. 81-116.

JÁnosi, A. 2019. Adatok a szívinfarktus miatt kezelt betegek ellátásának helyzetéről. Nemzeti Szívinfarktus Regiszter, 2014-2018. (Data on health care of infarction patients. Hungarian Myocardial Infarction Registry, 2014-2018). Cardiologia Hungarica 49. 249-254.

Kelejian, H.H. and Prucha, I.R. 2010. Specification and estimation of spatial autoregressive models with autoregressive and heteroskedastic disturbances. Journal of Econometrics 157. (1): 53-67.

Kiss, A., Kiss, N. and Váradi, B. 2019. Do Budget Constraints Limit Access to Health Care? Evidence from PCI Treatments in Hungary. Budapest, Budapest Institute. Available at http://www.budapestinstitute. eu/tvk_ami.pdf

KJÆR, T. and Grrd-Hansen, D. 2008. Preference heterogeneity and choice of cardiac rehabilitation program: Results from a discrete choice experiment. Health Policy 85. (1): 124-132.

Koós, B. 2015. A szegénység és depriváció a magyar településállományban az ezredfordulót követően - avagy kísérlet a települési deprivációs index létrehozására (Poverty and deprivation in Hungarian settlements after the Millennium - an attempt at creating a rural deprivation index). Tér és Társadalom 29. (1): 53-68.

LeSAGE, J. and PACE, R.K. 2009. Introduction to Spatial Econometrics. STATISTICS: Textbooks and Monographs. London-New York, Taylor \& Francis Group.

Levesque, J.F., Harris, M.F. and Russell, G. 2013. Patient-centred access to health care: conceptualising access at the interface of health systems and populations. International Journal for Equity in Health 12. (18): 1-9.

Link, B.G. and Phelan, J. 1995. Social conditions as fundamental causes of disease. Journal of Health and Social Behavior 35. 80-94.

Marmot, M. 2015. The Health Gap - The Challenge of an Unequal World. London, Bloomsbury Press.

McIntyre, D., Thiede, M. and Birch, S. 2009. Access as a policy-relevant concept in low-and middle-income countries. Health Economics, Policy and Law 4. 179-193.
Mérték Review, 2017. Fókuszterület: Szívinfarktusellátás (Focusing on health care of infarction). Budapest, ÁEEK.

Nagy, Cs., Juhász, A., Beale, L. and Páldy, A. 2011. Mortality amenable to health care and its relation to socio-economic status in Hungary, 2004-2008. European Journal of Public Health 22. (5): 620-624.

ORD, J.K. and Getis, A. 1995. Local spatial autocorrelation statistics: Distributional issues and an application. Geographical Analysis 27. (3): 286-306.

Patel, A.B., Waters, N.M. and Ghali, W.A. 2007. Determining geographic areas and populations with timely access to cardiac catheterization facilities for acute myocardial infarction care in Alberta, Canada. International Journal of Health Geographics 6(47): Available at https://doi.org/10.1186/1476-072X-6-47

Penchansky, R. and Thomas, W.J. 1981. The concept of access: definition and relationship to consumer satisfaction. Medical Care 19. (2): 127-140.

Rodrigues, E.J., Simpson, E., Richard, H. and Pilote, L. 2002. Regional variation in the management of acute myocardial infarction in the province of Quebec. Canadian Journal of Cardiology 18. (10): 1067-1076.

Samuels, G. 2005. Availability, Accessibility and Affordability. The Challenge of Diseases of Poverty. Presentation to WHO Commission on Intellectual Property Rights, Innovation and Public Health. Available at http://www.who.int/intellectualproperty/events/OpenForum GillSamuels.pdf?ua=1

Seghieri, C., Berta, P. and Nuti, S. 2019. Geographic variation in inpatient costs for acute myocardial infarction care: Insights from Italy. Health Policy 123. (5): 449-456.

Seidel, J.E., Ghali, W.A., Faris, P.D., Bow, C.J., Waters, N.M., Graham, M.M., Galbraith, P.D., Mitchell, L.B., Knudtson, M.L and APPROACH Investigators 2004. Geographical location of residence and uniformity of access to cardiac revascularization services after catheterization. Canadian Journal of Cardiology 20. (5): 517-523.

SHAH, T.I., Bell, S. and Wilson, K. 2016. Spatial accessibility to health care services: Identifying underserviced neighbourhoods in Canadian urban areas. PLoS ONE 11. (12): e0168208. Available at https:// doi.org/10.1371/journal.pone.0168208

Sibley, L.M. and Glazier, R.H. 2009. Reasons for self-reported unmet healthcare needs in Canada: a population based provincial comparison. Healthcare Policy 5. 87-101.

Skinner, J. 2012. Causes and consequences of regional variations in health care. In Handbook of Health Economics. Vol. 2. Eds.: Pauly, M., McGuire, T. and Barros, P., North Holland, Elsevier, 45-93.

TARIQ, S. and Woodman, J. 2013. Using mixed methods in health research. Journal of the Royal Society of Medicine Short Reports 4(6). Available at https://doi. org/10.1177/2042533313479197. 
Uzzoli, A., Bán, A., Beke, Sz., Pál, V. and Vitrai, J. 2019a. Health inequality and its regional disparities in Hungary: A case study on the role of access to health care. In An in Depth Look at Hungary. Ed.: Rompa, E., New York, NOVA Science Publishers, $1-50$.

Uzzoli, A., PÁl, V., Beke, Sz. and Bán, A. 2019b. Egészségegyenlőtlenség, hozzáférés, térbeliség-A szívizominfarktus ellátásának néhány földrajzi jellegzetessége Magyarországon (Health inequality, access to health care, spatiality - Cardiac care of acute myocardial infarction and its geographical features in Hungary). Földrajzi Közlemények 143. (2): 107-123.

Voss, P.R., Long, D.D., Hammer, R.B. and Friedman, S. 2006. County child poverty rates in the US: a spatial regression approach. Population Research and Policy Review 25. 369-391.

Waters, H.R. 2000. Measuring equity in access to health care. Social Science Medicine 51. 599-612.

WhiteheAd, M. 1992. The concepts and principles of equity and health. International Journal of Health Service 22. (3): 429-445.
Wilkins, E., Wilson, L., Wickramasinghe, K., Bhatnagar, P., Leal, J., Luengo-Fernandez, R., Burns, R., Rayner, M. and Townsend, N. 2017. European Cardiovascular Disease Statistics 2017. Brussels, European Heart Network. Available at http://www.ehnheart.org/images/CVD-statisticsreport-August-2017.pdf

Wilkinson, R. and Pickett, K. 2010. The Spirit LevelWhy Equality is Better for Everyone. London, Penguin.

Wispom, J. and Creswell, J.W. 2013. Mixed Methods: Integrating Quantitative and Qualitative Data Collection and Analysis While Studying PatientCentered Medical Home Models. AHRQ Publication No: 13-0028-EF.

YE, H. 2016. Geography of Health Care Access: Measurement, Analyses and Integration. PhD dissertation. Knoxville, The University of Tennessee.

Yonemoto, N., Kada, A., Yokoyama, H. and Nonogi, H. 2018. Public awareness of the need to call emergency medical services following the onset of acute myocardial infarction and associated factors in Japan. Journal of International Medical Research 46. (5): 1747-1755. 